\title{
Author Correction: Transcriptome profiling of mouse colonic eosinophils reveals a key role for eosinophils in the induction of s100a8 and s100a9 in mucosal healing
}

Hadar Reichman ${ }^{1}$, Italy Moshkovits ${ }^{1}$, Michal Itan $^{1}$, Metsada Pasmanik-Chor ${ }^{2}$, Thomas Vogl ${ }^{3}$, Johannes Roth ${ }^{3}$ \& Ariel Munitz ${ }^{1}$

Correction to: Scientific Reports https://doi.org/10.1038/s41598-017-07738-z, published online 02 August 2017

The original version of this Article contained errors in the spelling of the authors Hadar Reichman, Italy Moshkovits, Michal Itan, Metsada Pasmanik- Chor, Thomas Vogl, Johannes Roth \& Ariel Munitz which were incorrectly given as Reichman Hadar, Moshkovits Itay, Itan Michal, Pasmanik-Chor Metsada, Vogl Thomas, Roth Johannes \& Munitz Ariel.

In addition, in the original version of this Article, Figures 1 and 2 were inadvertently published as Figures 2 and 1. The Figure legends were correct from the time of publication.

These errors have now been corrected in the PDF and HTML versions of the Article and the Supplementary Information file that accompanies the Article.

(i) Open Access This article is licensed under a Creative Commons Attribution 4.0 International (c) License, which permits use, sharing, adaptation, distribution and reproduction in any medium or format, as long as you give appropriate credit to the original author(s) and the source, provide a link to the Creative Commons license, and indicate if changes were made. The images or other third party material in this article are included in the article's Creative Commons license, unless indicated otherwise in a credit line to the material. If material is not included in the article's Creative Commons license and your intended use is not permitted by statutory regulation or exceeds the permitted use, you will need to obtain permission directly from the copyright holder. To view a copy of this license, visit http://creativecommons.org/licenses/by/4.0/.

(C) The Author(s) 2018

\footnotetext{
${ }^{1}$ Department of Clinical Microbiology and Immunology, The Sackler School of Medicine, Tel-Aviv University, Ramat Aviv, 69978, Israel. 'Bioinformatics Unit, George S. Wise Faculty of Life Sciences, Tel Aviv University, Tel Aviv, 64239, Israel. ${ }^{3}$ Institute of Immunology, University of Münster, Münster, Germany. Correspondence and requests for materials should be addressed to A.M. (email: arielm@post.tau.ac.il)
} 